\title{
Determination of Trace Elements in Ruby Laser Crystals by Neutron Activation Analysis
}

\author{
Barbara A. Thompson and Eric C. Miller* \\ Institute for Materials Research, National Bureau of Standards, Washington, D.C. 20234
}

(March 30, 1971)

\begin{abstract}
Methods are described by which concentration levels have been determined for up to ten different trace elements and upper limits established for over 40 additional elements at the parts per million level or below in ruby crystals using neutron activation analysis. This information is required to determine the effect of trace element levels on laser performance. With conventional analytical methods difficulties arise because of both the refractory and insulating properties of the material. Because the crystals cannot be readily dissolved, the activation analysis was carried out nondestructively, irradiating the samples with highly thermalized neutrons to minimize formation of ${ }^{24} \mathrm{Na}$ and ${ }^{27} \mathrm{Mg}$ from $(n, \alpha)$ and $(n, p)$ reactions on the $\mathrm{Al}_{2} \mathrm{O}_{3}$ matrix, and using a $47-\mathrm{cm}^{3} \mathrm{Ge}(\mathrm{Li})$ detector.
\end{abstract}

Key words: Activation analysis; $\mathrm{Al}_{2} \mathrm{O}_{3}$; interfering reactions; laser; nondestructive analysis; ruby; trace elements.

\section{Introduction}

In order to determine the effect of trace element concentrations on the performance of ruby laser crystals, information is required for as many elements as possible at the ppm and ppb levels. This means obtaining good analytical data on single crystals of $\alpha$ - $\mathrm{Al}_{2} \mathrm{O}_{3}$ containing small amounts $(\sim 0.1 \%$ or less $)$ of $\mathrm{Cr}_{2} \mathrm{O}_{3}$. Because $\mathrm{Al}_{2} \mathrm{O}_{3}$ is an excellent insulator, it is difficult to spark and thus presents problems for analytical methods such as emission spectroscopy and spark source mass spectrometry which require an electrically conducting sample. Various techniques for overcoming this difficulty have been tried, including sputtering with gold and mixing ground samples with graphite, but they have met with limited success. Obviously, the problem of possible introduction of contaminants in either of these procedures is very serious.

For neutron activation analysis, however, the ruby crystals are nearly ideal samples. The principal radionuclide formed from the $\mathrm{Al}_{2} \mathrm{O}_{3}$ matrix is ${ }^{28} \mathrm{Al}$ which has a $2.3 \mathrm{~min}$ half-life and thus presents no interference to the measurement of trace element activities after a 30 to $60 \mathrm{~min}$ decay period. During this time the shortlived nuclides formed from oxygen will also decay away as will most of the $9.5 \mathrm{~min}{ }^{27} \mathrm{Mg}$ produced by the action of fast neutrons on aluminum. The only significant matrix activity will be ${ }^{24} \mathrm{Na}$, also formed from aluminum by fast neutrons. This information is summarized in table 1.

*NSF Summer Fellow; present address: West Virginia University, Morgantown, W. Va. 26505.
Because of these favorable nuclear properties much attention has been given to the determination of trace elements in aluminum metal by neutron activation analysis, beginning with the classic work of Albert and co-workers (1) and continuing to the present (2). At ultratrace levels however, these analyses have usually required chemical separations and so have been utilized less with $\mathrm{Al}_{2} \mathrm{O}_{3}$ than with $\mathrm{Al}$ metal because of the very refractory nature of the oxide. Weiner, O'Connor, and Rubin (3) have reported determining the Cr dopant in ruby crystals and Ortega (4) has determined Er and Ir where Er was added as a dopant. Both analyses were carried out using nondestructive neutron activation analysis and $\mathrm{NaI}(\mathrm{T} 1)$ detectors.

With the current availability of high resolution $\mathrm{Ge}(\mathrm{Li})$ detectors of good efficiency, it should be possible to determine many elements in the ruby crystals at the levels required, without chemical separations. This paper describes the procedures by which concentration levels were quantitatively determined for as many as ten different trace elements and upper limits established for over 40 additional elements at the ppm level or below in several different ruby crystals.

TABLE 1. Neutron reactions of aluminum and oxygen

\begin{tabular}{l|l}
\hline \hline \multicolumn{1}{c|}{ Reaction } & Product half-life \\
\hline${ }^{27} \mathrm{Al}(n, \gamma)^{28} \mathrm{Al}$ & $2.3 \mathrm{~min}$ \\
${ }^{27} \mathrm{Al}(n, p){ }^{27} \mathrm{Mg}$ & $9.5 \mathrm{~min}$ \\
${ }^{27} \mathrm{Al}(n, \alpha){ }^{24} \mathrm{Na}$ & $15 \mathrm{~h}$ \\
${ }^{18} \mathrm{O}(n, \gamma){ }^{19} \mathrm{O}$ & $27 \mathrm{~s}$ \\
${ }^{16} \mathrm{O}(n, p){ }^{16} \mathrm{~N}$ & $7 \mathrm{~s}$ \\
${ }^{17} \mathrm{O}(n, p){ }^{17} \mathrm{~N}$ & $4 \mathrm{~s}$ \\
\hline
\end{tabular}




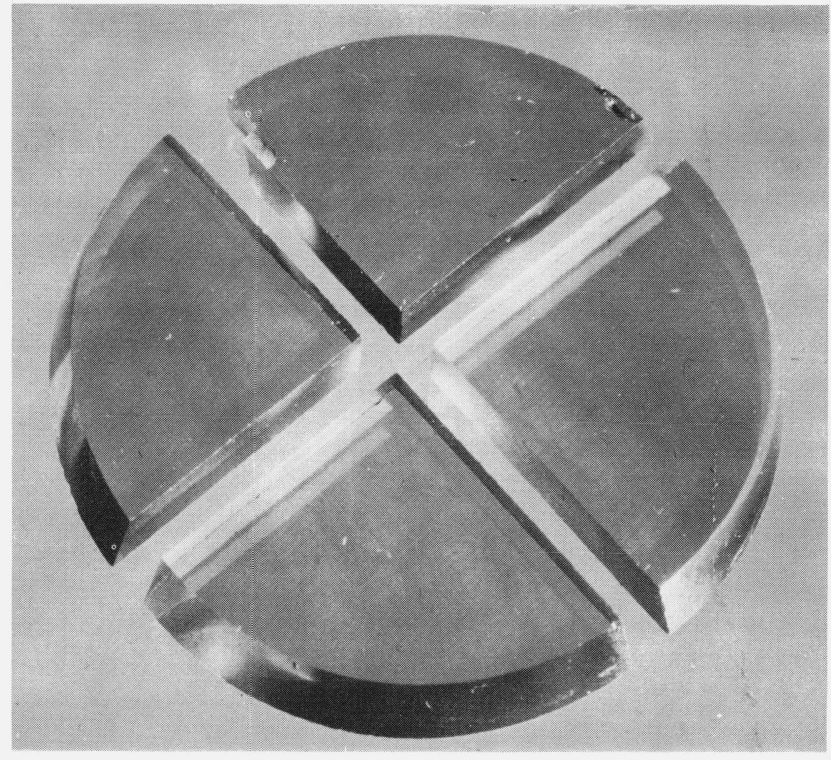

FigURE 1. Ruby crystal as cut for analysis, diameter $\sim 2.5 \mathrm{~cm}$.

\section{Experimental Detail}

The ruby boules analyzed had been grown by the Czochralski method and were obtained from commercial sources as part of a continuing study of high temperature materials and laser materials (5). Samples for analysis were cut with two parallel sides and had similar cross-sectional areas. This assured a reproducible counting geometry which could be duplicated in the standards. These conditions must be met in order to obtain accurate and precise results. Figure 1 shows a crystal slice which has been cut into sections for analysis. If the material could be dissolved readily, the reproducible counting geometry could be achieved with samples of any shape, by dissolving them and making the solution up to a standard volume for counting. However, because of the extreme insolubility of $\alpha-\mathrm{Al}_{2} \mathrm{O}_{3}$ this approach was not feasible.

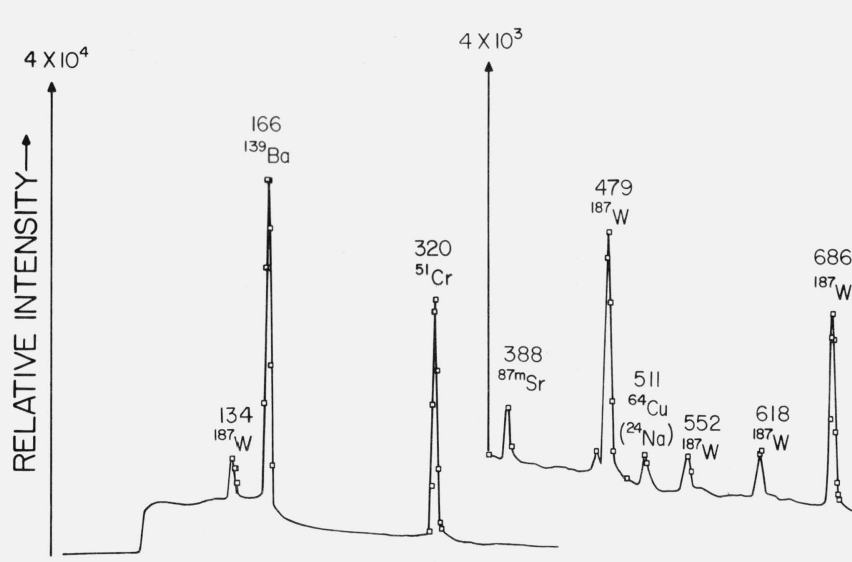

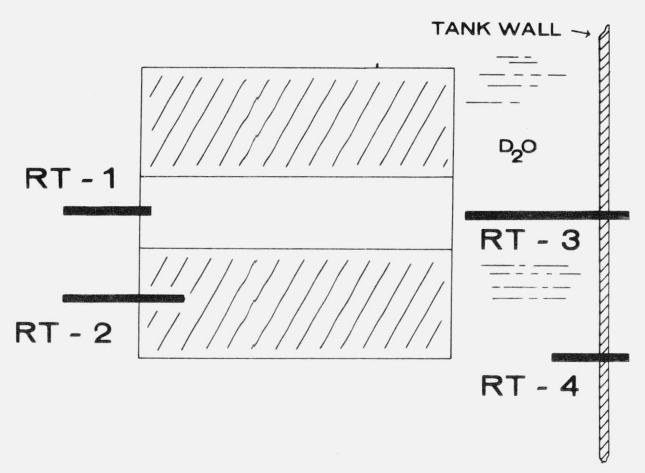

Figure 2. Positions of pneumatic tube terminals in the NBS Reactor.

The ruby slices to be analyzed, 0.4- $\mathrm{g}$ in weight, were heat-sealed in medical-grade polyethylene tubing and irradiated for $1 \mathrm{~h}$ in pneumatic tube RT-4 of the National Bureau of Standards Reactor. The thermal neutron flux in this facility is about $1 \times 10^{13}{ }_{\mathrm{n}} \cdot \mathrm{cm}^{-2} \mathrm{~s}^{-1}$. Figure 2 shows the locations of the four pneumatic tube facilities of the NBS Reactor relative to the reactor core (shaded area). Of the four facilities RT-4 has the highest ratio of thermal to fast neutrons. The use of this facility for the ruby irradiations thus minimizes the production of $15-\mathrm{h}{ }^{24} \mathrm{Na}$ which, as noted above, is formed by the action of fast neutrons on aluminum. A small copper foil flux monitor (1-2 mg) was taped to the outside of each polyethylene capsule to permit normalization of small differences in neutron flux or irradiation time from sample to sample.

After irradiation the samples were allowed to stand for at least $30 \mathrm{~min}$ to reduce the intense activity from ${ }^{28} \mathrm{Al}$. They were then rinsed in acetone and $1: 1 \mathrm{HNO}_{3}$ to remove surface contamination and transferred to polyethylene snapcap vials for counting. Each sample was counted at several different times using a $47-\mathrm{cm}^{3}$ $\mathrm{Ge}(\mathrm{Li})$ detector and a 2048-channel pulse height analyzer. Figure 3 shows a typical gamma ray spectrum of a crystal containing small amounts of $\mathrm{Ba}, \mathrm{Sr}, \mathrm{W}$, $\mathrm{Cu}, \mathrm{Ga}$, and $\mathrm{Mn}$ in addition to the $\mathrm{Cr}$ dopant. This

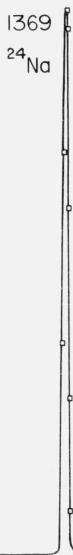

FIGURE 3. Gamma ray spectrum of irradiated ruby crystal; 100 min count, 3 h after irradiation. 
spectrum was recorded at about three hours after irradiation. Except for the ${ }^{139} \mathrm{Ba}$ and ${ }^{51} \mathrm{Cr}$ photopeaks, the most intense gamma ray is the $1369 \mathrm{keV}$ peak of ${ }^{24} \mathrm{Na}$. To determine whether this was all due to the fast neutron reaction on the aluminum in the matrix, some crystals were irradiated in both RT-3 and RT-4, with a cooling period of about a month between irradiations to be sure that all ${ }^{24} \mathrm{Na}$ had decayed away. As figure 2 indicates, RT-3 terminates closer to the reactor core and thus has a substantially higher ratio of fast to thermal neutrons than RT-4. In both irradiations the "concentration" of sodium, in $\mu \mathrm{g} / \mathrm{g}$, was calculated by comparison to a standard of pure sodium carbonate irradiated under the same conditions. If the ${ }^{24} \mathrm{Na}$ were being produced by the reaction of thermal neutrons with trace amounts of sodium in the rubies, the concentration would be the same for both irradiations. However, if the sodium were being produced by fast neutrons from the $\mathrm{Al}$ in the matrix, its "concentration" would be higher in RT-3 because of the higher proportion of fast neutrons. In this case the observed sodium level could be expected to be inversely proportional to the cadmium ratio. As table 2 shows, the sodium "concentration" does increase in RT-3 relative to $\mathrm{RT}-4$ and the increase is very similar to the decreases in the cadmium ratios for both gold and copper which have been determined for these two facilities (6). Thus, it seems reasonable to conclude that in these crystals all the ${ }^{24} \mathrm{Na}$ observed is generated from the aluminum in the crystal itself. Again, if the crystals could be readily dissolved, the ${ }^{24} \mathrm{Na}$ could be removed by passing the solution through a column of hydrated antimony pentoxide (7); however, with such insoluble material it is more reasonable to choose the irradiation conditions to minimize its formation.

Concentration levels of the observed trace elements were determined by comparison with standards irradiated under the same conditions as the samples. After irradiation the standards were dissolved in a few drops of suitable solvent in a polyethylene vial having about the same cross-sectional area as the samples and sufficient solvent added to give a solution of the same thickness as the samples. This produced the same counting geometry for both samples and standards and thus provided for optimum accuracy of the results. Pure $\mathrm{BaCO}_{3}$ and $\mathrm{SrCO}_{3}$ were used as $\mathrm{Ba}$ and $\mathrm{Sr}$ standards and primary standard $\mathrm{K}_{2} \mathrm{Cr}_{2} \mathrm{O}_{7}$ was used as a $\mathrm{Cr}$ standard. For most of the other elements the standards were either pure metals or oxides.

TABLE 2. ${ }^{27} \mathrm{Al}(\mathrm{n}, \alpha){ }^{24} \mathrm{Na}$ background in ruby crystals

\begin{tabular}{c|c|c|c}
\hline $\begin{array}{c}\text { NBSR } \\
\text { facility }\end{array}$ & $\begin{array}{c}\text { "ppm" } \\
\mathrm{Na}\end{array}$ & $\begin{array}{c}\text { Cadmium } \\
\text { ratio } \\
(\mathrm{Cu})(6)\end{array}$ & $\begin{array}{c}\text { Cadmium } \\
\text { ratio } \\
(\mathrm{Au})(6)\end{array}$ \\
\hline RT-3 & 7.9 & 80.5 & 16.5 \\
RT-4 & $\begin{array}{c}1.2 \\
\text { Ratio }\end{array}$ & $\begin{array}{c}582 \\
\mathrm{~b} 7.6\end{array}$ & $\begin{array}{c}111 \\
\mathrm{~b}\end{array} 6.7$ \\
\hline
\end{tabular}

RT $-3 / \mathrm{RT}-4$

RT $-4 /$ RT -3 .

\section{Results and Discussion}

To date a total of fifteen samples of eight different ruby boules have been analyzed by the method described above. Two samples of very pure synthetic sapphire crystal, prepared by a vapor-phase growth technique (8), have also been analyzed. Some of the results obtained are shown in table 3 which lists data on duplicate samples of four different crystals. For crystals "A" and "B" the duplicates are adjacent vertical slices while the duplicates for " $C$ " and "D" are horizontally adjacent sections as shown in figure 1 .

This listing is fairly typical of the crystals analyzed. Some of the others contained additional trace elements such as Co, La, and Au. The synthetic sapphires had a much higher purity than the rubies. The only trace elements detected were $\mathrm{Mn}, 0.0005 \mu \mathrm{g} / \mathrm{g} ; \mathrm{Cu}, 0.03$ and $0.04 \mu \mathrm{g} / \mathrm{g} ; \mathrm{Sc}, 0.010 \mu \mathrm{g} / \mathrm{g}$; and $\mathrm{Ir}, 0.0005$ and $0.002 \mu \mathrm{g} / \mathrm{g}$. The presence of readily detectable amounts of $\mathrm{Ir}$ in all the Czochralski rubies was a surprise initially, but was quickly accounted for when it was learned that the crystals had been grown using Ir crucibles. With the system used in this work for gamma ray spectrometry the $317 \mathrm{keV}$ peak of ${ }^{192} \mathrm{Ir}$ and the $320 \mathrm{keV}$ peak of ${ }^{51} \mathrm{Cr}$ overlap, as shown in figure 4 . The concentration of $\mathrm{Ir}$ can be determined from the $468 \mathrm{keV}$ gamma ray, but since ${ }^{51} \mathrm{Cr}$ has no other gamma rays, a correction must be made to obtain accurate results. This was accomplished by determining the area of the $296 \mathrm{keV}$ peak of ${ }^{192} \mathrm{Ir}$, calculating the area of the $317 \mathrm{keV}$ peak from the published decay scheme (8) and subtracting this value from the total area of the $320 \mathrm{keV}$ peak to obtain the ${ }^{51} \mathrm{Cr}$ contribution. The spectrum shown in figure 4 is from crystal " $A$ " which has $0.24 \mu \mathrm{g} / \mathrm{g}$ Ir. This is the highest Ir level observed in any of the crystals and thus requires the largest correction to the ${ }^{51} \mathrm{Cr}$ peak. For most crystals the Ir level is about 50 times lower and the correction is quite small.

Except for ${ }^{51} \mathrm{Cr}$ and ${ }^{192} \mathrm{Ir}$ the radionuclides used for the determination of all the trace elements listed in table 3 have half-lives shorter or comparable to that of the $15-\mathrm{h}{ }^{24} \mathrm{Na}$ generated from the matrix. As is shown in figure 3 , many of the gamma ray peaks from the trace elements were quite small relative to that of ${ }^{24} \mathrm{Na}$. This illustrates the extreme importance of minimizing the formation of ${ }^{24} \mathrm{Na}$ from the matrix during irradiation. In the case of copper the interference from ${ }^{24} \mathrm{Na}$ is especially serious because the decay of ${ }^{24} \mathrm{Na}$ results in the production of significant amounts of the same $511 \mathrm{keV}$ annihilation radiation as that from ${ }^{64} \mathrm{Cu}$ which is used to determine the copper concentration. The relative amount of this $511 \mathrm{keV}$ radiation formed from ${ }^{24} \mathrm{Na}$ depends on the particular detector used and for the $47-\mathrm{cm}^{3} \mathrm{Ge}(\mathrm{Li})$ detector employed in these analyses was 3.9 percent of the $1369 \mathrm{keV}$ photopeak. The peak areas for ${ }^{64} \mathrm{Cu}$ were corrected accordingly.

The results in table 3 show that $\mathrm{Cr}, \mathrm{Ga}$, and $\mathrm{Ir}$ are distributed quite homogeneously within a given crystal, while $\mathrm{Ba}$ and $\mathrm{Sr}$ exhibit extreme fluctuations. Since these fluctuations occur between adjacent horizontal sections as well as adjacent vertical slices, some sort of precipitation or other segregation of $\mathrm{Ba}$ and $\mathrm{Sr}$ 


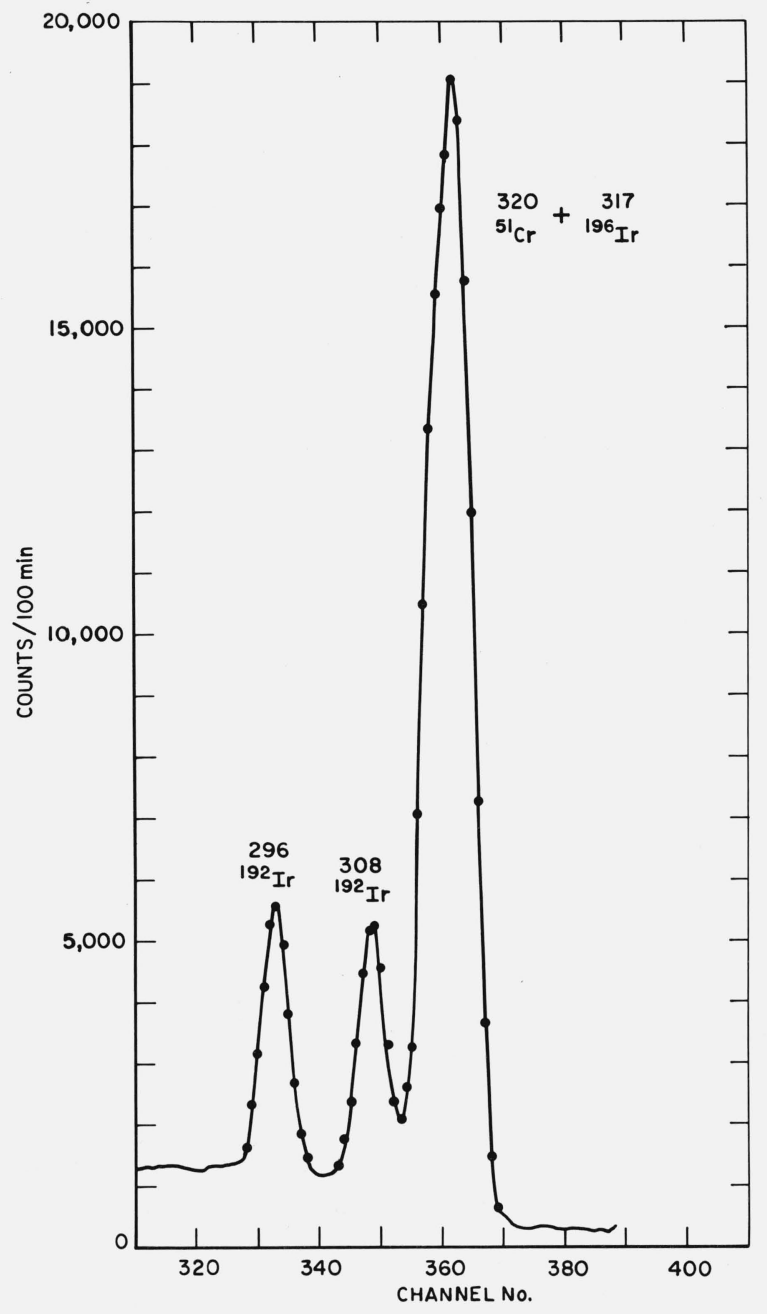

FIGURE 4. ${ }^{51} \mathrm{Cr}$ and ${ }^{192} \mathrm{Ir}$ gamma rays in irradiated ruby crystal.

seemed probable. The differences in crystal structure between $\mathrm{BaO}, \mathrm{SrO}$ (cubic) and $\mathrm{Al}_{2} \mathrm{O}_{3}, \mathrm{Cr}_{2} \mathrm{O}_{3}, \mathrm{Ga}_{2} \mathrm{O}_{3}$ (hexagonal) are consistent with a nonuniform distribution. To investigate this possibility further, the two sections of crystal " $D$ " were submitted for examination with the electron probe microanalyzer. Section 1 showed a uniform low level of $\mathrm{Ba}$, but section 2 was found to have many barium-rich inclusions in which the
Ba concentration was as high as 25 percent. One cluster of these inclusions is shown in figure 5 . The bright areas in the photograph are formed by the $\mathrm{Ba}$ $\mathrm{x}$ rays excited by the electron beam.

\section{Detection Limits for Other Elements}

Although only the elements noted above were actually observed in the crystals analyzed, it is possible to determine upper concentration limits for many other elements which could have been detected if present. Table 4 lists these detection limits as well as those for the elements observed in one or more samples. Like any set of detection limits, these are completely arbitrary and are valid only for the particular conditions used in this work, including the $47-\mathrm{cm}^{3}$ $\mathrm{Ge}(\mathrm{Li})$ detector used for counting. These conditions are summarized at the end of table 4. Obviously, in the case of some element of special interest the irradiation time or counting time could be increased or a detector of higher efficiency could be used to improve the sensitivity. Many of these detection limits are experimentally measured values; the others were calculated from nuclear constants, relating the analytical gamma ray to one of similar energy which had been measured. The limits in table 4 assume no interference from other gamma rays except, as noted, for ${ }^{51} \mathrm{Cr}$ and ${ }^{192} \mathrm{Ir}$.

$\mathrm{Na}$ and $\mathrm{Mg}$ are not listed in table 4 because they are subject to interference from the matrix as shown in table 1 and thus are not detectable except at relatively high levels. Sn is not listed because its detection limit is so high $(2000 \mu \mathrm{g} / g)$ that the presence of trace amounts could not be detected by this method. Other elements not listed in table 4 produce radionuclides which either have very short half-lives or do not emit gamma rays and so would not be detected under the conditions used in this work, even if present.

\section{Summary}

In summary, neutron activation analysis has been shown to be a useful method for the determination of many trace elements in ruby crystals at the ppm level and below. For some elements, the method has provided information about homogeneity as well as concentration.

TABLE 3. Results of activation analysis of four ruby crystals ${ }^{\mathrm{a}}$

\begin{tabular}{|c|c|c|c|c|c|c|c|c|}
\hline \multirow{2}{*}{$\begin{array}{c}\text { Trace } \\
\text { Element }\end{array}$} & \multicolumn{2}{|c|}{ Crystal "A" } & \multicolumn{2}{|c|}{ Crystal "B" } & \multicolumn{2}{|c|}{ Crystal "C" } & \multicolumn{2}{|c|}{ Crystal "D" } \\
\hline & 1 & 2 & 1 & 2 & 1 & 2 & 1 & 2 \\
\hline Cr.. & 152 & 147 & 302 & 317 & 255 & 240 & 266 & 258 \\
\hline Ga.. & 3.05 & 2.98 & 0.014 & 0.016 & 0.008 & $<0.006$ & 0.030 & 0.031 \\
\hline Ir.... & 0.239 & 0.245 & .050 & .054 & .045 & .041 & .052 & .051 \\
\hline $\mathrm{Mn} . .$. & .001 & .002 & & .002 & .0008 & .0006 & .0009 & .0056 \\
\hline $\mathrm{Cu} \ldots$ & .075 & .062 & .026 & .060 & .024 & .016 & .027 & .137 \\
\hline Ba.... & 42.6 & .24 & 15.2 & 1.26 & .28 & 1.74 & 16.5 & 265 \\
\hline Sr........ & 1.55 & $<.2$ & 0.49 & 0.066 & $<.03$ & 0.085 & 0.54 & 8.3 \\
\hline $\mathrm{W} \ldots \ldots \ldots$ & 0.032 & .052 & .015 & .030 & $<.01$ & $<.01$ & $<.01$ & $<0.01$ \\
\hline
\end{tabular}

${ }^{a}$ All results are expressed in units of $\mu \mathrm{g} / \mathrm{g}$. 


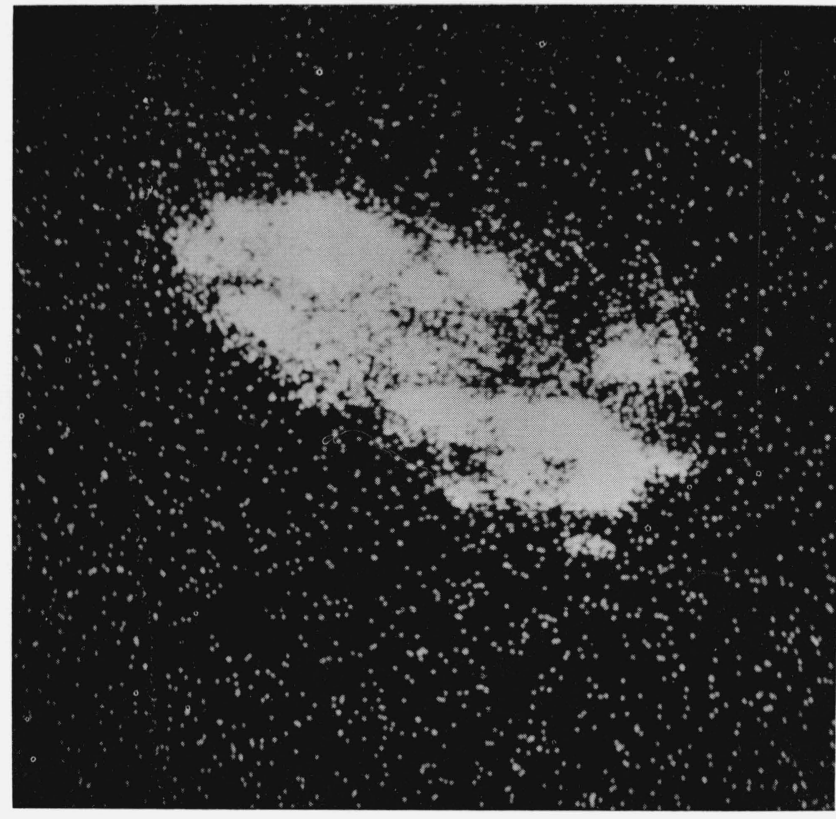

FiguRE 5. Scanning x-ray image of Ba-rich inclusions in ruby crystal, Ba L $\alpha_{1}, 4.6 \mu / \mathrm{cm}$.

The authors thank K. F. J. Heinrich and C. E. Fiori, also of the Analytical Chemistry Division, NBS, who conducted the electron probe microanalysis investigation. Special thanks are due to G. W. Cleek and J. L. Torgesen of the Inorganic Materials Division and the Institute for Materials Research, NBS, who provided samples and many helpful discussions. This work was supported in part by ARPA. This paper was presented in part at the 159th National Meeting, American Chemical Society, Houston, Texas, February 1970.

\section{References}

[1] Albert, P., Caron, M., and Chaudron, G., Compt. rend. 233, 1108 (1951); Albert, P., Ann. Chim. 13, 827-96 (1956).
TABLE 4. Detection limits ${ }^{\mathrm{a}}$ for trace elements in ruby, $\mu \mathrm{g} / \mathrm{g}$

\begin{tabular}{cl|cl|cl|cc}
\hline \hline $\mathrm{Ag}$ & 0.05 & $\mathrm{Eu}$ & 0.0005 & $\mathrm{Mn}$ & 0.0005 & $\mathrm{Sr}$ & 0.05 \\
$\mathrm{Ar}$ & .1 & $\mathrm{Fe}$ & 5 & $\mathrm{Mo}$ & .05 & $\mathrm{Ta}$ & .1 \\
$\mathrm{As}$ & .002 & $\mathrm{Ga}$ & 0.003 & $\mathrm{Nd}$ & 1 & $* \mathrm{~Tb}$ & .2 \\
$\mathrm{Au}$ & .0001 & $\mathrm{Gd}$ & .02 & $\mathrm{Ni}$ & 1 & $\mathrm{Te}$ & .6 \\
$\mathrm{Ba}$ & .1 & ${ }^{*} \mathrm{Ge}$ & .2 & ${ }^{2} \mathrm{Os}$ & 0.01 & $* \mathrm{Th}$ & .02 \\
$\mathrm{Br}$ & .01 & $\mathrm{Hf}$ & .001 & $\mathrm{Pd}$ & 10 & $* \mathrm{Tm}$ & .02 \\
$\mathrm{Cd}$ & 2 & $* \mathrm{Hg}$ & .5 & $\mathrm{Pr}$ & 0.05 & $* \mathrm{U}$ & .02 \\
$* \mathrm{Ce}$ & 0.1 & $\mathrm{Ho}$ & .2 & $* \mathrm{Pt}$ & .03 & $\mathrm{~W}$ & .01 \\
$\mathrm{Cl}$ & .05 & $\mathrm{I}$ & .01 & $\mathrm{Rb}$ & 1 & $\mathrm{Xe}$ & .01 \\
$\mathrm{Co}$ & .01 & $\mathrm{In}$ & .0001 & $* \mathrm{Re}$ & 0.001 & $\mathrm{Yb}$ & .01 \\
$\mathrm{Cr}$ & 1 & $\mathrm{Ir}$ & .005 & $\mathrm{Ru}$ & 1 & $\mathrm{Zn}$ & .5 \\
$\mathrm{Cs}$ & 0.5 & $\mathrm{~K}$ & 1 & $\mathrm{Sb}$ & 0.02 & $\mathrm{Zr}$ & 100 \\
$\mathrm{Cu}$ & .005 & $\mathrm{Kr}$ & 1 & $\mathrm{Sc}$ & .05 & & \\
$\mathrm{Dy}$ & .001 & $\mathrm{La}$ & 0.003 & $\mathrm{Se}$ & 3 & & \\
$* \mathrm{Er}$ & .005 & $* \mathrm{La}$ & .02 & $\mathrm{Sm}$ & 0.001 & & \\
\hline
\end{tabular}

a These elements would be observed if present in ruby at or above the levels indicated, as summing the following conditions: $1 \mathrm{~g}$ sample, $1 \mathrm{~h}$ irradiation at $10^{13} \mathrm{n} \cdot \mathrm{cm}^{-2} \mathrm{~s}^{-1}, 1 \mathrm{~h}$ cooling time for decay of ${ }^{28} \mathrm{Al}, 10 \mathrm{~min}$ counting time for short-lived activities $\left(T_{1 / 2}<2 \mathrm{~h}\right), 100 \mathrm{~min}$ counting time for short-lived activities $\left(T_{1 / 2}>2 \mathrm{~h}\right)$, all counting done with $47-\mathrm{cm}^{3} \mathrm{Ge}(\mathrm{Li})$ detector. For elements marked * the limit will be about a factor of ten poorer in the presence of $\mathrm{Ir}$ and $\mathrm{Cr}$ at the levels normally observed to date.

[2] For a detailed listing see Activation Analysis: A Bibliography, Lutz, G. J., Boreni, R. J., Maddock, R. S., Meinke, W. W., Eds., Nat. Bur. Stand. (U.S.), Tech. Note 467, 264 pages (Dec. 1969).

[3] Weiner, J. R., O'Connor, J. J., and Rubin, B., J. Electrochem. Soc. $110,1160(1963)$.

[4] Ortega, R. F., Modern Trends in Activation Analysis, Nat. Bur. Stand. (U.S.), Spec. Publ. 312, Vol. 1, 691 pages (1969) (see pp. 536-540).

[5] ARPA-NBS Program of Research on High Temperature Materials and Laser Materials, Franklin, A. D., and Bennett, H. S., Eds., Nat. Bur. Stand. (U.S.), Tech. Note 531, 75 pages (June 1970).

[6] Becker, D. A., and LaFleur, P. D., Activation Analysis Section: Summary of Activities, July 1969 to June 1970, Nat. Bur. Stand. (U.S.), Tech. Note 548,165 pages (1970) (see p. 14).

[7] Gills, T. E., Marlow, W. F., and Thompson, B. A., Anal. Chem. 42, 1831 (1970).

[8] Parker, H. S., and Harding, C. A., J. Am. Ceramic Soc. 53, 583 (1970).

[9] Lederer, C. M., Hollander, J. M., and Perlman, I., Table of Isotopes, Sixth Edition (John Wiley and Sons, Inc., New York, 1967).

(Paper 75A5-676) 